\section{Obtrusive energy}

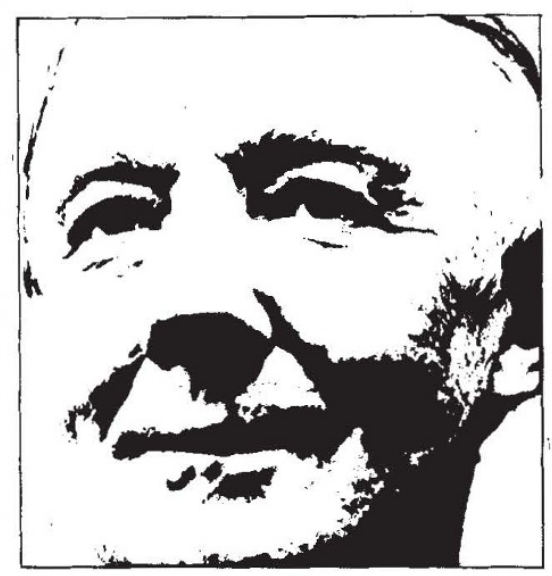

KENNETH MELLANBY

EVERYONE knows that the Earth's supplies of fossil fuels are finite, and that petroleum and natural gas, our most convenient energy sources, will be seriously depleted by the end of this century. The wisdom of replacing these by nuclear power, particularly the fast breeder reactor, is controversial. There is general agreement that natural renewable energy - solar radiation, wind, waves, the tidesshould be more widely used, though there is disagreement about the magnitude of the contribution they will make. Conservationists are particularly enthusiastic, and perhaps over optimistic, about these natural sources, largely because they appear to be non-polluting and because it is imagined that they will not harm the environment.

This is partly true. Energy obtained directly or indirectly from the sun will not affect the heat balance of the globe, nor will it release large amounts of the gaseous oxides of carbon, sulphur or nitrogen. It does not add to the levels of radiation. But it may have other effects which are less acceptable than is commonly imagined.

The "wind bloweth where it listeth", but in many places it does so with sufficient consistency to supply energy which may be trapped with windmills. To most people a windmill is a picturesque erection of the kind formerly common in the fenlands of East Anglia and the Netherlands, now rarely seen unless maintained by the efforts and funds of preservationist groups. The modern windmill is very different; it is both more effective and more obtrusive. At the admirable UK National Centre for Alternative Technology near Machynlleth in Wales useful work on windpower is in progress. Various types of windmill of different sizes are being evaluated.
Unfortunately a large modern machine on a hill top is criticised by many local people who consider that it causes serious "visual pollution". If we wish to make a significant contribution (say $10 \%$ ) to the power supply of any developed country then huge shiny erections will become a major feature of the landscape, with a greater impact than that made by the much-criticised pylons which now carry the cables of the electricity grid.

Solar power collection may be thought to be less obtrusive. Small panels on roofs are less pleasing to look at than thatch or eighteenth century pantiles, but they can be hidden or disguised. However, they can only make a minor contribution to single households. To collect solar energy on an industrial scale needs something very different. Although the total energy received by the earth from the sun is several thousand times that used by man's present activities, it is spread very diffusely even in the sunniest areas. Our present largest electrical generating stations, using coal, oil or nuclear energy, with an output of three megawatts, cover only a few acres and in some cases skilful landscape architects make them relatively unobtrusive. It is probable that at some future date improved techniques will enable solar energy of a comparable amount to be collected at an economic cost, but with the sort of efficiency that is suggested by present studies many square miles of collecting panels will be needed. Thus, for the United States, an area of collectors of over 50,000 square miles has been suggested to meet current use, and although this is under $2 \%$ of the total land area, their location will present problems. These will be even more serious in crowded countries like England. The situation might be expected to be easier in the deserts of the Sahara in Africa and in Australia, particularly suitable because of the intensity of the sunlight.

However, there would probably still be a very vocal opposition, led by many of those who are at present the most enthusiastic apostles of the use of solar cnergy. Thus in Australia today there is strong opposition to uranium mining, particularly from organised conservation groups. This is partly based on fears of the dangers of radiation, but also on environmental grounds. Even a proposed mining site of a few acres in a region of almost uninhabited desert is said to be of unique ecological importance, as well as being a sacred site of the aborigines. Solar panels covering thousands of square miles should surely be subject to similar objections.

\section{Fast breeder delay would help proliferate weapons}

ANY attempt to delay the development of the fast breeder nuclear reactor could increase, rather than decrease, the danger of the proliferation of nuclear weapons, according to a report by the Rockerfeller Foundation.

The report is sharply critical of moves by President Carter to slow down the development of the fast breeder--in particular by terminating the Clinch River breeder project-on the grounds that the widespread use of plutonium would increase the likelihood of proliferation.

It argues that the United States should not only resume intensive development of the fast breeder, but also attempt to create a joint demonstration programme with other nations now committed to fast breeders.

The report, which was prepared by a Washington-based consulting firm International Energy Associates Limited, points out that most of these countries have already made the breeder part of their long-term energy plans. "Regardless of what the US decides, they are unlikely to alter or defer their own breeder programmes significantly", it says.

Any unilateral attempt by the US to delay breeder development could backfire by increasing the concern of other countries about potential shortages in fuel supply. This would lead to "more rapid and less considered deployment of breeders".

The report argues that a more realistic way of imposing control on breeder development would be to press for stricter international controls on the construction and placement of breeder fuel facilities.

\section{And then there were three}

The European Space Agency has taken the next step along the road to deciding who will be the sole European payload specialist aboard the first Spacelab mission in 1980. Last week it whittled down the number of candidates from four to three. The three to go on to the next stage of the decision-making process are Ulf Merbold (Germany), Claude Nicollier (Switzerland) and Wubbo Ockels (Netherlands). The final choice will not be made until just a few months before the flight. The unsuccessful candidates will have the consolation of working as ground-based specialists for the flight at NASA's Johnson Space Center. In the meantime, all three will become part of the Spacelab Payload Integration and Coordination in Europe (SPICE) team and undergo intensive training in Germany and the US. 